\title{
Análise preliminar dos resultados do "Projeto redes de referências para a agricultura familiar": estudo de caso de uma propriedade
}

\section{Preliminary analysis of the results of the project "Reference networks for family agriculture": a property case study}

\author{
Anaís Naomi Kasuya Saldanha ${ }^{1} ;$ Márcia Regina Gabardo da Câmara²; \\ Dimas Soares Júnior ${ }^{3}$; Adenir de Carvalho ${ }^{4}$
}

\begin{abstract}
Resumo
Este trabalho procurou analisar as contribuições socioeconômicas decorrentes do acompanhamento realizado pelo Projeto Redes de Referências para a Agricultura Familiar, o qual está sendo desenvolvido no Estado do Paraná, desde 1998, numa parceria entre o entre o Instituto Agronômico do Paraná (IAPAR) e a Empresa Brasileira de Assistência Técnica e Extensão Rural (EMATER/PR). Esta análise consiste em duas etapas: primeiro, a realização de uma análise econômico-financeira, com base nos dados coletados em uma das propriedades acompanhadas, buscando identificar se houve um incremento na renda dessa família e uma melhor utilização dos fatores de produção (terra, capital e mão de obra); na segunda etapa do trabalho, por meio de uma entrevista com questionário semi-estruturado, procurou-se identificar e analisar a perspectiva do agricultor familiar acerca da participação neste projeto, bem como seu grau de satisfação.
\end{abstract}

Palavras-chave: Agricultura familiar. Gestão de Propriedades Familiares Rurais. Pesquisa Agropecuária.

\begin{abstract}
The purpose of this work was to analyze the social-economical contributions from the followup procedure carried out by the Project: Reference Networks for Family Agriculture, which is being developed in the State of Paraná since 1998, in partnership with the Agronomical Institute of Paraná (IAPAR) and the Rural Extension and Technical Assistance Company of the State of Paraná (EMATER/PR). This analysis consists of two stages: firstly, the accomplishment of an economical-financial analysis, based on the data gathered in one of the followed-up properties, trying to identify if there was an increase in the income of this family and a better use of the production factors (land, capital and labor); secondly, by means of an interview with a semistructured questionnaire, it was tried to identify and analyze the family farmer's perspective about his participation in this project as well as his level of satisfaction.

Key words: Family agriculture. Rural Family Properties Management. Agricultural research.

\footnotetext{
${ }^{1}$ Mestre em Administração pela Universidade Estadual de Maringá - UEM. E- mail: anaissaldanha@ yahoo.com.br

${ }^{2}$ Professora do Departamento de Economia da Universidade Estadual de Londrina. E - mail: mgabardo@ sercomtel.com.br

${ }^{3}$ Pesquisador da Área de Sócio-economia do Instituto Agronômico do Paraná e Mestre em Administração pela Universidade Estadual de Londrina E- mail: dimasjr@iapar.br

${ }^{4}$ Extensionista da Empresa Brasileira de Assistência Técnica e Extensão Rural - EMATER/PR
} 


\section{Introdução}

O objetivo deste trabalho é apresentar e analisar os resultados de acompanhamento de uma das propriedades que estão sendo acompanhadas pelo Projeto Redes de Referências para a Agricultura Familiar $^{5}$. Este projeto está sendo desenvolvido no Estado do Paraná, desde 1998, numa parceria entre o Instituto Agronômico do Paraná (IAPAR) e a Empresa Brasileira de Assistência Técnica e Extensão Rural (EMATER/PR).

No Brasil, o debate sobre a agricultura familiar ainda é recente e não possui contornos definidos. Os estudos de Abramovay (1985) e Abramovay (1992) salientam que a agricultura familiar é uma forma reconhecida e legitimada na maioria dos países desenvolvidos, nos quais a estrutura agrária é majoritariamente composta por explorações nas quais o trabalho da família assume uma importância decisiva. Para melhor compreender os conceitos a serem utilizados neste trabalho, a agricultura familiar será definida, segundo Mussoi (2002), como:

Uma forma de vida, que tem (seus atores sociais) um saber/conhecimento construído histórica e coletivamente; que tem uma lógica própria de decisão; tendo uma relação harmônica com o meio ambiente (ou pelo menos, muito mais harmônica que a agricultura empresarialcapitalista convencional); usando de forma articulada e eficiente o trabalho familiar; baseando-se num processo de diversificação produtiva que garanta a produção para o abastecimento próprio e a necessária integração com o mercado local/regional, garantindo também níveis adequados de biodiversidade (produtiva, medicinal, artesanal e de reserva biológica); sendo capaz de processar muitos dos produtos por ela produzidos e reciclar dejetos para sua re-utilização. Este tipo de agricultura é, a nível externo, capaz de se articular no seu conjunto, possibilitando a resolução organizada/coletiva de seus problemas, uso de potencialidades e instrumentos de produção.

Estas características lhes proporcionam mecanismos próprios de resistência ao processo de "modernização" convencional. Isso torna o trabalho da pesquisa e extensão rural voltado para este segmento da agricultura um tanto quanto complexo, pois esses trabalhos devem respeitar e condizer com a lógica e realidade desses agricultores.

De modo geral, os princípios econômicos que se aplicam à indústria e ao comércio são também válidos para a agricultura, entretanto esta tem certas características que devemos ter presentes ao estudar a economia de uma empresa agrícola (HOFFMANN et al., 1984). Como ressaltado por Lima et al. (1995), deve-se sempre atentar para a necessidade de se analisar a maneira com que o produtor organiza sua propriedade transmitindo-lhe a importância de se atualizar, em faces das muitas mudanças que estão ocorrendo na economia.

No Brasil, a agricultura familiar é responsável pela geração de sete vezes mais postos de trabalho por unidade de área, do que a agricultura patronal (INSTITUTO NACIONAL DE COLONIZAÇÃO E REFORMA AGRÁRIA, 1995). Também no Paraná os principais produtos agrícolas são produzidos por propriedades familiares, utilizando-se a mão de obra de homens, mulheres, crianças e idosos da família. Ao analisar os dados descritos por Doretto et al. (2000), pode-se comprovar a importância deste estrato de produtores para a economia do estado, segundo os quais, no Paraná 90\% dos estabelecimentos agropecuários são familiares. Tais estabelecimentos detêm $55,7 \%$ da área total, empregam $83 \%$ do pessoal ocupado e são responsáveis por $57 \%$ do valor bruto da produção vegetal.

\footnotetext{
${ }^{5}$ O Projeto das Redes de Referências para a Agricultura Familiar será detalhadamente apresentado mais adiante e para maior facilidade na redação e leitura do trabalho, este será designado apenas por Projeto Redes.
} 
É fundamental analisar e compreender de que maneira são utilizados os recursos naturais, os meios técnicos e a mão de obra disponível. Isto impõe, necessariamente, o conhecimento das condições locais de produção ou, como salienta Abramovay (1985), busca-se não somente o aumento da produção e o rendimento dos produtores, mas principalmente, o sistema de produção que melhor se adapta ás condições ecológicas e sócio - econômicas. De acordo com Souza (1986), duas hipóteses explicam o baixo nível de adoção de tecnologia por pequenos agricultores ou a transferência é inadequada, ou a tecnologia proposta não é apropriada às suas condições, sendo essa última a causa mais comum.

A produção agrícola sofreu uma profunda e intensa transformação neste século, em decorrência da modernização tecnológica, principalmente nos países industrializados. A transferência dessas tecnologia modernas aos demais países foi feita, muitas vezes, sem o devido cuidado de adaptação às realidades locais. A introdução dessas tecnologias, no Brasil, aprofundou a diferenciação social já existente no meio rural, além de agravar os problemas sociais na cidade, a partir, da chegada em massa, dos agricultores que foram expulsos.

O processo de modernização partia da premissa de que a simples transferência de tecnologias melhoradas promoveria o desenvolvimento econômico de uma dada região. No entanto, essas categorias de agricultores não apresentavam condições de recursos materiais e financeiros para absorverem os pacotes tecnológicos propostos, uma vez que estes pacotes não estavam adequados as suas realidades. O enfoque de pesquisa que orientou o processo de modernização baseia-se no controle de todos os fatores, exceto um ou alguns que se deseja estudar. Isso significa pesquisar, em estação experimental e/ou laboratórios, apenas uma parte do sistema de produção, considerando fatores de caráter técnico e desprezando-se as questões sócio-econômicas. Concluída a pesquisa de uma nova tecnologia, ela é gerada como peça isolada e depois oferecida aos agricultores para ser incluída em seus sistemas.
A dinâmica de desenvolvimento, especialmente num sistema ao serviço de agricultores, requer uma alta flexibilidade para poder reagir rapidamente às mudanças sócio - econômicas, infra-estruturais e técnicas. A participação dos agricultores nos programas voltados para a agricultura familiar, baseiase na autoconfiança, compreensão e confiança por parte de todos os envolvidos (SCHMITZ, 2001). O conhecimento aprofundado dos sistemas de produção dos agricultores permite selecionar tecnologias promissoras que podem ser introduzidas a partir de testes nos estabelecimentos agrícolas, da experimentação em meio real (nas áreas de produção dos agricultores) ou, depois de validação, em estações experimentais deslocadas para áreas rurais. Poderse-ia, também, reorientar as prioridades de pesquisa agronômica para atender as necessidades maiores de todos ou certos tipos de agricultores em função da política geral do país.

$\mathrm{O}$ artigo está estruturado em cinco partes, a saber: introdução; procedimentos metodológicos do artigo; a descrição do Projeto Redes; apresentação dos resultados e as considerações finais, item no qual se buscou identificar em que aspectos o acompanhamento do Projeto foi relevante para o desempenho da propriedade nos últimos cinco anos.

\section{Procedimentos Metodológicos para a Realização da Análise Quantitativa e da Análise Qualitativa}

O objetivo proposto por este trabalho é apresentar e analisar os resultados alcançados por uma das propriedades acompanhadas pelo Projeto Redes nestes cinco anos de acompanhamento. Para consecução desse objetivo, foi realizada primeiramente uma análise quantitativa das informações econômico - financeira e dos resultados de produção, coletados pelo Projeto Redes. Nessa análise, buscou-se demonstrar as alterações ocorridas na propriedade durante os anos agrícolas de 1998 a 2003. Em seguida, apresenta-se a análise qualitativa, por meio de uma entrevista realizada com 
Saldanha, A. N. K; Câmara, M. R. G; Junior, D. S; Carvalho, A.

o agricultor, da propriedade selecionada para a análise dos dados quantitativos. Com todo esse estudo, buscou-se identificar, sob a perspectiva do agricultor, em que aspectos o acompanhamento do Projeto foi relevante para o desempenho da propriedade nos últimos cinco anos.

Quadro 1. Indicadores Econômicos - Financeiros
O objeto de estudo do trabalho foi uma das pequenas propriedades acompanhadas pelo Projeto Redes, da região de Apucarana, norte do Estado do Paraná. A escolha deste agricultor foi determinada pelo fato de este ser um dos primeiros participantes do projeto. As informações relevantes para discussão do Projeto Redes que analisa o desempenho das unidades familiares são apresentadas no Quadro 1.

Fonte: Soares Júnior e Saldanha, 2000

\begin{tabular}{|c|c|c|c|c|c|}
\hline \multicolumn{6}{|l|}{ 1. Medidas de dimensionamento } \\
\hline $\begin{array}{l}\text { 1.1 Superficie Agricola Útil - SAU (há) } \\
\text { Terras trabalhadas ou exploradas pelo produtor não } \\
\text { importando se próprias, arrendadas ou sob qualquer } \\
\text { outra condição legal. É calculada subtraindo-se da } \\
\text { área total as áreas que não se incluem no conceito. }\end{array}$ & \multicolumn{5}{|c|}{$\begin{array}{l}\text { Área Total } \\
\text { - áreas com matas plantadas el ou nativas } \\
\text { - áreas inaproveitáveis } \\
\text { - áreas com construções el ou benfeitorias } \\
\text { - áreas com estradas el ou carreadores } \\
\text { = Superficie Agricola Útil }\end{array}$} \\
\hline \multirow{7}{*}{$\begin{array}{l}\text { 1.2 Equivalente Homem - Eq. H. (Unidade) } \\
\text { Unidade padrão de mão-de-obra utilizada para } \\
\text { avaliar a disponibilidade e calcular a remuneração } \\
\text { do fator trabalho na exploração agrícola; trabalho de } \\
\text { um adulto em tempo integral em um ano (300 dias/ano). } \\
\text { Para uniformizar a mão de obra, dados gênero, idade e } \\
\text { possibilidade de dedicação da mão de obra disponivel } \\
\text { utilizou-se a tabela ao lado. }\end{array}$} & & \multicolumn{2}{|c|}{ ESTUDA } & \multicolumn{2}{|c|}{ NÃO ESTUDA } \\
\hline & $I D A D E$ & Masc & Fem & Masc & Fem \\
\hline & 07 a 13 & 0,25 & 0,25 & 0,50 & 0,50 \\
\hline & $14 a 17$ & 0,33 & 0,33 & 0,66 & 0,66 \\
\hline & 18 a 24 & 0,50 & 0,50 & 1,00 & 1,00 \\
\hline & 25 a 59 & - & - & 1,00 & 1,00 \\
\hline & 60 ou mais & - & - & 0,50 & - \\
\hline $\begin{array}{l}\text { 1.3 Capital Total - KT (RS) } \\
\text { Expressa a disponibilidade total de capital do produtor segundo } \\
\text { as diferentes classificações deste fator, apresentadas em } \\
\text { parênteses, após a descrição dos itens ao lado. }\end{array}$ & $\begin{array}{l}\text { Valor atual das } \\
\text { (fundiário) } \\
+ \text { Valor dos ani } \\
+ \text { Valor dos rep } \\
\text { + Valor atual dc } \\
\text { inanimado) } \\
\text { + Valor dos inst } \\
+ \text { Valor do reba } \\
\text { Capital Total }\end{array}$ & $\begin{array}{l}\text { ações, } \\
\text { le trab } \\
\text { res e } \\
\text { quinas } \\
\text { (explor } \\
\text { ara en }\end{array}$ & $\begin{array}{l}\text { itoria } \\
\text { explo } \\
\text { es (ex } \\
\text { ipame } \\
\text { circu } \\
\text { el ou }\end{array}$ & $\begin{array}{l}\text { Ituras } \\
\text { fixo vi } \\
\text { cáo fix } \\
\text { explor } \\
\text { (expl }\end{array}$ & $\begin{array}{l}\text { nentes } \\
\text { ixo } \\
\text { circulante) }\end{array}$ \\
\hline \multicolumn{6}{|l|}{ 2. Custos } \\
\hline \multicolumn{6}{|c|}{$\begin{array}{l}2.1 \text { Custos Variáveis Totais CVT (R\$) } \\
\text { Custos que se alteram de acordo a decisão gerencial do administrador acerca do nível de produçã̃ no periodo de } \\
\text { tempo considerado. Incluem o valor dos insumos utilizados na produção vegetal e animal, valor da mão de obra } \\
\text { contratada e contribuição ao INSS }\end{array}$} \\
\hline \multicolumn{6}{|c|}{$\begin{array}{l}2.2 \text { Custos Fixos Totais - CFT (R\$) } \\
\text { São aqueles que existem mesmo que os recursos não sejam utilizados, não variando quando muda o nivel de produção, não se } \\
\text { encontram no curto prazo sob o controle do administrador. Englobam principalmente as depreciações e a mão-de-obra extra-familiar } \\
\text { permanente }\end{array}$} \\
\hline \multicolumn{6}{|l|}{ 3. Receitas } \\
\hline \multicolumn{6}{|c|}{$\begin{array}{l}3.1 \text { Renda Bruta de Produção - RBP (R\$) } \\
\text { Corresponde a renda gerada na propriedade pelas atividades de produção vegetal e animal. Engloba o valor das vendas, } \\
\text { auto-consumo, cessões internas, produtos usados como pagamento em espécie e diferenças no estoque. }\end{array}$} \\
\hline \multicolumn{6}{|c|}{$\begin{array}{l}3.2 \text { Outras Rendas - OR (R\$) } \\
\text { Outros ingressos monetários na exploração - aposentadorias, salários e o valor monetário mão de obra vendida. }\end{array}$} \\
\hline 3.3 Renda Bruta Total-RBT (R\$) & \multicolumn{5}{|c|}{$R B T=R B P+O R$} \\
\hline $\begin{array}{l}\text { 4. Margem Bruta Total-MBT (R\$) } \\
\text { Diferença entre a Renda Bruta e os Custos Variáveis. Contribuição para } \\
\text { os Custos Fixos e Lucros depois dos Custos variáveis serem pagos. }\end{array}$ & $M B T=R$ & & & & \\
\hline \multicolumn{6}{|l|}{ 5. Medida de Performance Global } \\
\hline $\begin{array}{l}\text { 5.1. Remuneração da Mão de Obra Familiar - } \\
\text { (R\$/Eq.h./mês) } \\
\text { Valor atribuido à mão-de-obra familiar, cujo custo não está incluido } \\
\text { nos demais indicadores. É obtido após os pagamentos dos juros, ou custo } \\
\text { de oportunidade, dos capitais fixos e variáveis, sendo calculados por } \\
\text { equivalente-homem por mês. }\end{array}$ & \multicolumn{5}{|c|}{$\begin{array}{l}\text { RLG } \\
\text { - Juros sobre capital fixo } \\
\text {-Juros sobre capital variável/Equivalente-homem/12 } \\
\text { = Remuneração da Mão de Obra Familiar }\end{array}$} \\
\hline
\end{tabular}


Para a análise quantitativa, foram utilizadas as informações dos registros efetuados pelos produtores em instrumentos de coleta de dados, formulados pelo Projeto. Em seguida, os dados foram repassados aos extensionistas da EMATER, os quais os armazenaram no software denominado de SAP - Sistema de Acompanhamento de Propriedades. Esse sistema, já preparado para receber informações técnicas e econômicas de cada propriedade, foi desenvolvido numa parceria entre a Organização das Cooperativas do Paraná - OCEPAR e o Serviço Nacional de Aprendizagem Rural - SENAR/PR. Também foram utilizados os relatórios das planilhas RPR'S (Redes de Propriedades de Referência), desenvolvido especialmente para facilitar e automatizar o cálculo dos indicadores globais de desempenho.

Para a caracterização e análise quantitativa do desempenho global dos sistemas de produção trabalhados, foi utilizado um conjunto de indicadores, proposto para o Projeto Redes, por Soares Júnior e Saldanha (2000), o qual está dividido em cinco grupos, a saber: dimensionamento, custos, receitas, margem bruta e performance global.

Para a análise qualitativa, o conceito de percepção é fundamental. Ele é uma dimensão chave na compreensão da difusão de idéias. Embora uma nova idéia possa ser considerada vantajosa pelos especialistas de algum campo, atores particulares poderão não perceber a inovação de forma semelhante. Assim, é essencial que o modelo para o comportamento de adoção leve em consideração a percepção do ator em relação à situação. Rogers (apud BURKE, 1977, p.11) define percepção como: "a maneira pela qual um indivíduo responde a qualquer sentido ou impressão que ele detecta". Percepção é uma função do campo situacional dentro do qual o indivíduo opera. O conhecimento dos campos situacionais, a maneira pela qual o indivíduo identificase a si próprio, seu senso de segurança e as regularidades normativas poderão permitir a especificação teórica de algumas das condições para o comportamento de adoção.
Realizou-se uma entrevista com o agricultor para analisar qualitativamente as transformações ocorridas nesta propriedade, identificar a importância e colaboração do projeto para essas modificações e verificar como o agricultor se vê dentro deste processo. Para a coleta das informações qualitativas, foi desenvolvido um questionário dividido em: aspectos gerais, aspectos técnicos, aspectos econômico-financeiro e algumas questões conclusivas.

\section{Projeto Redes de Referências para a Agricultura Familiar $^{6}$}

A afirmação da agricultura familiar no cenário social e político brasileiro está relacionada à legitimação que o Estado lhe emprestou, ao criar o Programa Nacional de Fortalecimento da Agricultura Familiar (PRONAF), em 1996. Esse programa, em larga medida, foi formulado como resposta às pressões do movimento sindical rural realizadas desde o início da década de 1990, e nasceu com a finalidade de prover crédito agrícola e apoio institucional às categorias de pequenos produtores rurais que vinham sendo alijados das políticas públicas ao longo da década de 1980 e encontravam sérias dificuldades de se manter na atividade. A partir do surgimento do PRONAF, o sindicalismo rural brasileiro, sobretudo aquele localizado nas regiões Sul e Nordeste, passou a reforçar a defesa de propostas que vislumbram o compromisso cada vez mais sólido do Estado com uma categoria social considerada específica e que necessitava de políticas públicas diferenciadas (juros menores, apoio institucional, etc.). Para apoio à agricultura familiar, o governo estabeleceu no Âmbito do Estado, o Programa Paraná 12 meses, e é dentro deste programa que se insere o Projeto das Redes de Referências para a Agricultura Familiar.

Com o objetivo de desenvolver e difundir sistemas de produção melhorados para a agricultura familiar paranaense, a Empresa Paranaense de Assistência Técnica e Extensão Rural (EMATER/PR) e o

\footnotetext{
${ }^{6}$ Descrição baseada na apresentação do Projeto Redes, publicado na "Revista Redes de Referências para a Agricultura Familiarapresentação do enfoque de trabalho através de descrições de propriedades acompanhadas.” Projeto Paraná 12 Meses, 2000.
} 
Instituto Agronômico do Paraná (IAPAR) vêm desenvolvendo desde 1998, o projeto "Redes de Referências para a Agricultura Familiar", integrante do Programa de Estado "Paraná 12 Meses", em seu componente Manejo e Conservação dos Recursos Naturais - Fase 2 (Modernização). A metodologia utilizada neste projeto surgiu de um convênio firmado com uma instituição de pesquisa francesa, que realiza este trabalho em toda a França, há 25 anos.

Uma nova tecnologia, selecionada com a participação dos agricultores, adapta-se localmente melhor do que aquela recomendada pelos técnicos que trabalham por conta própria. E mais ainda quando os agricultores estão presentes desde o início do processo de geração da tecnologia, o resultado é mais facilmente aceito pelos demais agricultores. Esse é o conceito que está sendo adotado no Projeto Redes. Nele se rejeita a idéia de que cada componente do sistema funciona isoladamente do meio ambiente e é independente dos outros componentes. A rede é tratada como uma abordagem holística, segundo a qual os sistemas devem ser tratados no seu conjunto, com ênfase principalmente deste com o meio ambiente e na interação das partes que o constituem.

O objetivo é o aumento da produção e dos produtos cultivados, aliado à escolha do sistema de produção que melhor se adapta às condições ecológicas e sócio-econômicas. Nesse caso, é fundamental procurar analisar e entender de que maneira é feita a utilização dos recursos naturais, dos meios técnicos e da mão de obra disponível. Logo, são necessários o conhecimento das condições locais de produção e a mudança de postura de pesquisadores e extensionistas. Para que a pesquisa e a extensão rural gerem e difundam tecnologias agrícolas que não sejam injustas, requer-se a correspondente reformulação ou adequação dos métodos, técnicas e procedimentos pedagógicos e de difusão a serem utilizados. Faz-se fundamental a utilização de instrumentos operacionais realmente adequados em função das características dos agricultores envolvidos.

O Projeto Redes constitui-se em uma metodologia inovadora que se propõe a enfrentar o desafio de construir um novo modelo de pesquisa e extensão rural para transpor os problemas aqui mencionados. Para isso, apoia - se em propriedades analisadas, planejadas e acompanhadas em seu conjunto (recursos naturais, produção vegetal e animal, recursos humanos e econômicos) com o enfoque sistêmico que, após apresentarem melhorias, são utilizadas como fontes de referências técnicas e econômicas ${ }^{4}$.

A partir do acompanhamento das propriedades, procura-se ajustar os sistemas de produção às potencialidades e limitações locais (de natureza agroecológicas e/ou econômicas), visando a atingir a maior rentabilidade possível, obedecidas às premissas de sustentabilidade. Isso torna esses sistemas passíveis de serem adotados por um grande número de agricultores. Essa forma de trabalho promove a adaptação de tecnologias para o desenvolvimento da agricultura e busca resolver o principal problema dos projetos de desenvolvimentos, que é a interação entre os agentes - pesquisadores, extensionistas e agricultores.

Os principais objetivos das Redes são: ofertar novas tecnologias e/ou atividades, ampliando as possibilidades de modernização; servir como pólo de demonstração de tecnologias e sistemas de produção para potencializar o processo de difusão; disponibilizar informações e propor métodos para orientar os agricultores na gestão da empresa agrícola; servir como base para a capacitação e treinamento de agentes de assistência técnica e extensão rural e de agricultores; possibilitar a identificação de demanda de novas linhas de pesquisa.

A instalação de uma rede envolve três etapas complementares: estudo prévio, escolha de sistemas

\footnotetext{
${ }_{3}^{3}$ Projeto Redes está inserido no Projeto Paraná 12 Meses, que é um programa do Governo do Estado do Paraná, que teve início em 1998 e visa promover o desenvolvimento econômico e social da população rural e o manejo e conservação dos recursos naturais, atuando em todo território estadual com apoio financeiro do BIRD e do Tesouro Estadual.

${ }^{4}$ Uma referência técnica e/ou econômica é um conjunto de informações sobre uma atividade agrícola que ajuda a assistência técnica na orientação dos agricultores na tomada de decisão.
} 
prioritários e seleção de propriedades. No estudo prévio, é realizada a delimitação de zonas homogêneas, com a caracterização das regiões trabalhadas no tocante aos aspectos de clima, solos, estrutura agrária e infra-estrutura. Realiza-se também a tipologia dos sistemas de produção, buscando identificá-los e caracterizá-los, com o objetivo de compreender sua lógica e entender as diferenças e particularidades que existem entre os agricultores.

A escolha dos sistemas prioritários depende das informações da etapa precedente e é realizada pelo comitê de coordenação regional que discute as hipóteses acerca da evolução desses sistemas de produção e suas consequiências (peso econômico, peso demográfico, evolução provável de seu número, influência do contexto sócio - econômico sobre os sistemas atuais, potencialidades de novos sistemas, etc.). A seleção das propriedades garante parte da eficácia dos trabalhos, por isso ela deve seguir o consenso entre os representantes dos agricultores e dos agentes de desenvolvimento. Feita a escolha da propriedade, o passo seguinte é realizar um diagnóstico, com o intuito de conhecer seu conjunto, seus pontos de estrangulamento, suas potencialidades e os objetivos do agricultor.

A partir dessas informações, o extensionista e o agricultor elaboram um projeto de médio prazo para a melhoria da propriedade. Na seqüência, o extensionista passa a acompanhar a implantação do projeto e registrar os resultados técnicos e econômicos que surgirão das mudanças e que servirão para construir as referências modulares e globais do sistema.

\section{Resultados: Análise Econômico - Financeira da Propriedade Acompanhada e a Percepção do Produtor Sobre o Projeto das Redes}

A propriedade selecionada para a realização desta análise encontra-se localizada no município de Apucarana, Região Norte do Estado do Paraná. E para uma melhor compreensão da análise apresentada, será feita a seguir, uma breve descrição da propriedade.

\footnotetext{
$\overline{{ }^{5} \mathrm{O} \text { nome do agricultor foi alterado, para manter sua privacidade. }}$
}

Natural de Boracéia, Estado de São Paulo, o Sr. João da Silva ${ }^{5}$ tem sua história fortemente vinculada à história da cafeicultura do Norte do Paraná. Mas a partir da segunda metade da década de 70 , a cafeicultura paranaense enfrenta um contínuo declínio na produção e área cultivada. O Norte do Paraná reconhece a expansão da soja e do trigo e, nessa época, o $S r$. João erradica parte de seu cafezal para dedicar-se ao cultivo de grãos.

Em 1988, passa a arrendar áreas para o plantio de milho, além de prestar serviços motomecanizados de preparo de solo e colheita. Deparando-se ao longo dos anos seguintes com a redução da rentabilidade dos cultivos em áreas arrendadas e a necessidade de deslocamento cada vez maiores, o Sr. João chega a 1995 pensando em novas alternativas. Era o ano no qual começava a popularizar-se o novo modelo tecnológico para a cafeicultura paranaense e o $S r$. João visualiza aí a possibilidade de voltar a produzir exclusivamente café em sua própria terra. Em 1996, planta 1,5 ha de café adensado, área que foi ampliada com o plantio de outros 1,3 ha no ano seguinte. Paralelamente, continua o plantio de grãos no próprio sítio e na área arrendada, contínua à sua, dedicando também maior atenção à pecuária leiteira, atividade que sempre explorara para o auto consumo.

Com relação à mão de obra, o Sr. João trabalha em conjunto com a esposa, o filho e a nora, priorizando a plena ocupação da mão de obra familiar na definição de suas estratégias, para, no futuro, alcançar a qualidade de vida desejada pela família. Entretanto, essa mão de obra não é suficiente para a realização de todas as tarefas de manejo de cultura, sendo necessário o pagamento de 180 diárias anuais nos períodos de capina e colheita.

\section{Resultado Quantitativo: Demonstrativo dos Resultados Econômico - Financeiros}

Os resultados encontrados na análise da remuneração da mão de obra familiar, da propriedade aqui analisada, mostraram-se bastantes satisfatórios, pois a remuneração mensal de cada pessoa(equivalente homem), subiu de $\mathrm{R} \$ 354,79$ em 1998, para $\mathrm{R} \$ 568,75$ em 2003. 


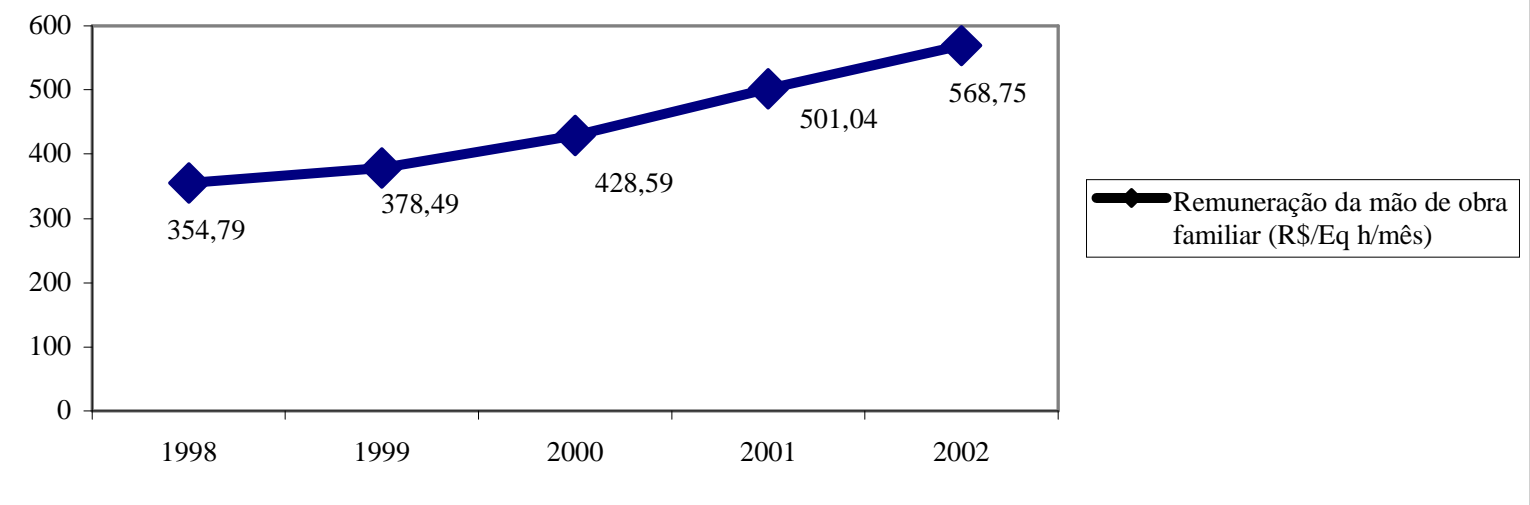

Gráfico 1. Medida de Performance Global - Remuneração da Mão de Obra Familiar (R\$/Eq.H/mês)

Analisando-se os resultados econômico - financeiros, pode-se verificar um aumento significativo no capital total deste produtor, passando de R \$38.102, $31 \mathrm{em} \mathrm{1998,} \mathrm{para} \mathrm{52.722,29} \mathrm{em} 2003$.

Tabela 1. Benfeitorias, Máquina e Equipamentos

\begin{tabular}{|l|c|l|c|}
\multicolumn{2}{c|}{1998} & \multicolumn{2}{c|}{$\mathbf{2 0 0 3}$} \\
\hline $\begin{array}{l}\text { Benfeitorias }(\mathrm{R} \$) \\
\text { Maquinas e }\end{array}$ & $14.151,62$ & Benfeitorias $(\mathrm{R} \$)$ & $15.941,93$ \\
\hline equipamentos $(\mathrm{R} \$)$ & 17.698 .03 & $\begin{array}{l}\text { Maquinas e } \\
\text { equipamentos }(\mathrm{R} \$)\end{array}$ & $20.955,90$ \\
\hline Total $(\mathrm{R} \$)$ & $31.849,65$ & Total $(\mathrm{R} \$)$ & $36.897,83$ \\
\hline
\end{tabular}

Tabela 2. Indicadores Técnicos - Medidas de Dimensionamento

\begin{tabular}{|l|c|c|c|c|c|}
\hline INDICADORES & $\mathbf{9 8 / 9 9}$ & $\mathbf{9 9 / 0 0}$ & $\mathbf{0 0 / 0 1}$ & $\mathbf{0 1 / 0 2}$ & $\mathbf{0 2 / 0 3}$ \\
\hline SAU (há) & 37,16 & 37,16 & 37,16 & 37,16 & 37,16 \\
\hline Eq. Homem (un.) & 3 & 3 & 2,5 & 3 & 2,5 \\
\hline Capital Total (R\$) & $38.102,31$ & $43.150,49$ & $43.150,49$ & $52.722,29$ & $52.722,29$ \\
\hline
\end{tabular}

Tabela 3. Indicadores Econômicos - Custos

\begin{tabular}{|l|c|c|c|c|c|}
\hline INDICADORES & $\mathbf{9 8 / 9 9}$ & $\mathbf{9 9 / 0 0}$ & $\mathbf{0 0 / 0 1}$ & $\mathbf{0 1 / 0 2}$ & $\mathbf{0 2 / 0 3}$ \\
\hline $\begin{array}{l}\text { Custos variáveis } \\
(\mathrm{R} \$)\end{array}$ & $10.170,00$ & $10.066,00$ & $13.609,23$ & $16.575,96$ & $23.099,76$ \\
\hline Custos fixos $(\mathrm{R} \$)$ & $3.000,00$ & $3.000,00$ & $3.000,00$ & $3.000,00$ & $3.000,00$ \\
\hline Custos totais & $13.170,00$ & $13.066,00$ & $16.609,23$ & $19.575,96$ & $26.099,76$ \\
\hline
\end{tabular}

Apesar dos custos da propriedade terem aumentado de $\mathrm{R} \$ 13.170,00$ para $\mathrm{R} \$ 26.099,76$, a renda bruta do Sr. João da Silva, teve um aumento ainda maior, passando de $\mathrm{R} \$ 29.676,00 \mathrm{em} 1998$, para $\mathrm{R} \$ 93.805,25 \mathrm{em}$ 2003, o que também permitiu que houvesse um aumento da margem bruta da propriedade. 
Tabela 4. Indicadores Econômicos - Receitas

\begin{tabular}{|l|c|c|c|c|c|}
\hline INDICADORES & $\mathbf{9 8 / 9 9}$ & $\mathbf{9 9 / 0 0}$ & $\mathbf{0 0 / 0 1}$ & $\mathbf{0 1 / 0 2}$ & $\mathbf{0 2 / 0 3}$ \\
\hline $\begin{array}{l}\text { Renda Bruta da } \\
\text { Produção (R\$) }\end{array}$ & $29.676,00$ & $42.417,00$ & $39.000,00$ & $70.530,04$ & $93.805,25$ \\
\hline Outras Rendas (R\$) & 00,00 & 00,00 & 00,00 & 00,00 & 00,00 \\
\hline $\begin{array}{l}\text { Renda Bruta Total } \\
\text { R \$) }\end{array}$ & $29.676,00$ & $42.417,00$ & $39.000,00$ & $70.530,04$ & $93.805,25$ \\
\hline $\begin{array}{l}\text { Margem Bruta } \\
\text { Total (R\$) }\end{array}$ & $16.506,00$ & $29.352,00$ & $22.390,77$ & $50.954,08$ & $67.705,49$ \\
\hline R\$/há & 444,19 & 789,87 & 602,55 & $1.371,21$ & $1.822,00$ \\
\hline
\end{tabular}

Para uma maior representatividade dos resultados econômico - financeiros apresentados, tornou-se interessante comparar a renda/ha anual encontrada nesta propriedade, com a renda/há anual apresentada recentemente no trabalho, Novo Retrato da Agricultura Familiar: O Brasil Redescoberto (INSTITUTO NACIONAL DE COLONIZAÇÃO E REFORMA AGRÁRIA, 2000). Essa obra permite comprovar a importância da agricultura familiar; o indicador de renda total por unidade de área (hectare) foi, na região Sul, de $\mathrm{R} \$ 241,00$ e $\mathrm{R} \$ 99,00$ para a agricultura familiar e patronal, respectivamente.

Com base nos resultados apresentados neste trabalho, pode-se observar que a renda total por unidade de área (hectare) evoluiu de $\mathrm{R} \$ 444,19$ na safra de $98 / 99$ para $\mathrm{R} \$ 1.822,00$ na safra de $02 / 03$, valores muito superiores a média brasileira. Isso sugere que houve uma melhor utilização dos recursos terra, capital e mão de obra, uma vez que a superfície agrícola útil (SAU) se manteve em 37,16 há, não havendo compra de terras e a mão de obra familiar se manteve entre 2,5 e 3 Eq.H. Os dados quantitativos foram confirmados pela análise qualitativa que revelou que na percepção do agricultor houve muitos benefícios e que tais benefícios são tangíveis (maior) receita e intangíveis(incremento no bem-estar familiar, o fato de estarem contentes).

\section{Resultado Qualitativo: a Percepção do Agricultor.}

Conforme foi descrito nos procedimentos metodológicos, a percepção do agricultor entrevistado envolveu aspectos gerais, aspectos técnicos, aspectos econômico-financeiros e algumas questões conclusivas.

Nas questões de aspectos gerais, procurou-se identificar o que levou o agricultor a participar do Projeto e também saber o que ele esperava desta participação. Pode-se verificar que ele não tinha uma idéia muito clara do que ia ser feito, mas agora se mostra satisfeito por saber quanto gasta e quanto ganha em cada atividade, como se pode perceber no discurso do Sr. João da Silva , quando afirma:

eu resolvi participa porque a gente sabe a renda que dá a renda que não dá, antes mesmo, ás vezes uma coisa que você achava que tava dando renda, na verdade você tava trabalhando no vermelho, né. E agora não, vai levando tudo marcado e então a gente sabe o que a gente pode continua e o que a gente não pode, né. O soja, nóis cumecemos plantar o soja, mas num tava sobrando. Pelo que nóis plantava, a saca por alqueire não tava sobrando, não tava correspondendo, né, então... Nós achemos que ia acontecer só de bom pra nóis, né. Nós falamos, né, porque nós faz as coisas e leva tudo marcadinho. 
Ajuda nóis pra chuchu, então eu acho que pra nóis foi uma boa

Quando se perguntou ao agricultor que tipo de controle ele realizava na propriedade, antes de começar a participar do Projeto, ele alega que não fazia nem um tipo de anotação, por isso não sabia por onde entrava e por onde saia o dinheiro, o $\mathrm{Sr}$. João da Silva informou que "não anotava nada. Era tanto de adubo, tanto de calcário, ia lá vendia tanto e nem sabia o que dava nem o que não dava, às vezes tirava do café pra ponha no milho ou no soja e achava que tava dando ainda, e não é o que tava dando, o que tava dando era o café."

Com relação aos aspectos técnicos, procurouse identificar se o agricultor tinha consciência das mudanças ocorridas no processo produtivo, houve também a preocupação em saber se o acompanhamento do Projeto colaborou para o aumento de sua produção e produtividade o Sr. João da Silva disse:

depois que nóis começo a trabalha junto, né. Através da EMATER ai, mudo porque nois diversifico, né. Ai entro com café, milho, leite, mudo totalmente. Nóis era tranqüilo pra chuchu. O que mudo bastante é que de primeiro nóis ficava envolvido com pranta roça arrendada, lembra. Teve época que nóis prantava 30, 40 alqueires de roça arrendada." (...) "Nossa, aumento. A gente consegue produzi mais, porque sei lá, a semente de milho mais produtiva né. Que em outros tempos se plantava uma semente de milho ai e parece que não produzia igual nos ta produzindo agora. Esse 90/ 90 é um milho bom. É deu pra vê que aumenta, por causa que nas colheita né, cada ano que passa parece que... Só que aumento também por causa de orientação certa, porque nóis tirava uma quantidade de milho por alqueire de 150 (sacas) no pau da viola e agora 300. Só que era pra da mais, porque nóis aqui bruto, em 2 alqueires nóis tiramo 940 saca de milho.
Buscando analisar a questão da gestão da propriedade, pode-se observar que o agricultor está muito vinculado ao extensionista que o acompanha e também ao acesso direto à EMATER, pois segundo o Sr. José da Silva:

Ficou mais fácil, porque qualquer dúvida a gente corre com eles lá e conversa com eles lá. Já tem orientação, já tão por dentro. Não tem nem comparação. Em outros tempos nóis levava no escuro, a miguelão, agora não, agora é diferente que a gente já sabe o que que ta dando, o que dá pra continuar e o que tem que largar. Que nem o barracão de frango, nóis tava afim de colocar, mas daí eles vieram e falaram que tem que pensa, vamo soma o negócio ai pra vê porque, eu acho que isso ia dá pra cabeça"

Nas questões conclusivas, procurou-se analisar o que o agricultor esta achando de participar do Projeto e mais uma vez, verificou-se o grande vínculo com o extensionista e com a EMATER , o Sr. João da Silva - “O que nóis podia dizer é que a EMATER ai, o pessoal da EMATER, ajuda bastante a gente. $O$ que agente precisa vai lá. Faz análise de terra não cobra nada de nóis."

Com a preocupação de melhorar o acompanhamento e o trabalho do Projeto Redes, perguntou-se ao agricultor o que pode ser feito para melhorar, mas devido a sua satisfação, ele não pode dar maiores contribuições e o Sr. João da Silva "A eu acho que pra nóis aqui ta bom demais eu to contente, pra nóis aqui ta beleza."

Analisando-se a entrevista realizada, observa-se que, apesar dos aspectos positivos da metodologia utilizada pelo Projeto, verifica-se que o agricultor está fortemente ligado ao extensionista, fato que futuramente poderá causar problemas, uma vez que o agricultor pode se estabilizar na situação atual, até se tornar ultrapassado, caso o acompanhamento seja interrompido. 


\section{Considerações Finais}

Nos últimos anos, muitos trabalhos vêm se dedicando aos estudos e análises das formas de organizações familiares. Segundo Abramovay (1992), pode-se extrair pelo menos dois ensinamentos: a) a existência de diferentes estratégias sociais e econômicas por meio das quais as populações, grupos e indivíduos identificados com a agricultura familiar vêm viabilizando sua reprodução social e sobrevivência econômica nas sociedades contemporâneas e b) o Estado tem sido o maior responsável pela manutenção de políticas e formas de apoio à expansão e à consolidação das unidades que se organizam e estruturam com base no trabalho familiar nas nações mais desenvolvidas,.

Daí a importância de instituições como o Instituto Agronômico do Paraná - IAPAR e a Empresa Brasileira de Assistência Técnica e Extensão Rural - EMATER/PR, desenvolverem trabalhos como o Projeto Redes. E, apesar de ainda não estarem mensurados os resultados dos cinco anos de acompanhamento desse projeto, a proposta mostrase bastante adequada ao segmento de agricultores familiares, pois a metodologia utilizada no desenvolvimento do projeto está voltada para questões técnicas e questões sociais destes agricultores.

\section{Referências}

ABRAMOVAY, R. Progresso Técnico: A Indústria é o caminho?. Cadernos de Difusão de Tecnologia, Brasília, v.2, p.233-245, 1985.

ABRAMOVAY, R. Paradigmas do Capitalismo Agrário em Questão. Campinas: UNICAMP/ Hucitec, 1992.

DORETTO, M.; LAURENTI, A. C.; DEL GROSSI, M. E. Diferenciação de Estabelecimentos Familiares na Agricultura Paranaense. Londrina: Instituto Agronômico do Paraná (IAPAR), 2000.
INSTITUTO NACIONAL DE COLONIZAÇÃO E REFORMA AGRÁRIA. Diretrizes de política agrária e desenvolvimento sustentável. Brasília: FAO/INCRA, 1985.

Novo Retrato da Agricultura Familiar: o Brasil redescoberto. Brasília: FAO/INCRA, 2000.

HOFFMANN, R.; ENGLER, J. J. C.; SERRANO, O.; THAME, A. C. M.; NEVES, E. M.. A Administração da Empresa Agrícola. Piracicaba: ESALQ/USP, 1984.

LIMA, A. P.; BASSO, N.; NEUMANN, P. S.; MÜLLER, A. G.; SANTOS, A. C. Administracao da unidade de producao familiar: modalidades de trabalhocom agricultores. Ijui: UNIJUI, 1995.

PARANÁ. Secretaria de Estado do Planejamento e Coordenação Geral. Manual operativo do projeto Paraná 12 meses. Curitiba, 1999.

MUSSOI, E. M. Agricultura familiar: transitando para onde? In: SIMPÓSIO LATINO AMERICANO SOBRE INVESTIGAÇÃO E EXTENSÃO EM PESQUISA AGROPECUÁRIA, 5., 2002, Florianópolis. Anais... Florianópolis: IESA/SBSP, 2002.

BURKE, T. J. A percepção e o processo de adoção de inovações na agricultura. Piracicaba, ESALQ/ USP 122p. (Tese de Mestrado), 1977, p.11

SCHMITZ, H. Reflexões sobre métodos participativos de inovação na agricultura. In: SIMÕES, A.; SILVA, L. M. S.; MARTINS, P. F. S.; CASTELLANET, C. (orgs.). Agricultura Familiar: Métodos e Experiências de Pesquisa Desenvolvimento. Belém: Universidade Federal do Pará, 2001.

SCHNEIDER, Sérgio. A pluriatividade na Agricultura Familiar. Porto Alegre: UFRGS, 2003. 
SOARES JÚNIOR, D.; SALDANHA, A. N. K. Indicadores econômicos propostos para a análise dos sistemas de produção e propriedades agropecuárias trabalhadas nas "Redes de Referências para a Agricultura Familiar" do estado do Paraná. SEMINÁRIO ESTADUAL DE ADMINISTRAÇÃO RURAL, 5., 2000, Itajaí. Anais...Itajaí: ABAR Núcleo Brasileiro, 2000.

SOUZA, R.; ANDRADE, J. G. Administração Rural: Um Enfoque Moderno. Informe Agropecuário, Belo Horizonte, n.143, p.3-5, 1986. 